\title{
Predictive value of serum uric acid in hospitalized adolescents and adults with acute asthma
}

\author{
This article was published in the following Dove Press journal: \\ Therapeutics and Clinical Risk Management \\ 14 November 2016 \\ Number of times this article has been viewed
}

\author{
Nasser Keshar Abdulnaby' \\ Ashraf Othman Sayed ${ }^{2}$ \\ Nehad Mohamed Shalaby ${ }^{3}$ \\ 'Chest Diseases and Tuberculosis \\ Department, Faculty of Medicine, \\ Cairo University, Cairo, ${ }^{2}$ Department \\ of Pediatrics, Children and Women's \\ University Hospital, Minia University, \\ El-Minya, ${ }^{3}$ Department of Pediatrics, \\ Mansoura University Children's \\ Hospital, Faculty of Medicine, \\ Mansoura University, Mansoura, Egypt
}

Correspondence: Nehad Mohamed Shalaby

Department of Pediatrics, Mansoura University Children's Hospital, Faculty of Medicine, Mansoura University, Algomhoriah Street, Mansoura, Postal Code 355 I I, Egypt

Tel +20 I0 93988813

Email amahalawy2002@yahoo.com
Background: High serum uric acid (sUA) is an indicator of oxidative stress and is linked to tissue hypoxia in asthma. The objective of this case series was to investigate the prognostic role of sUA in patients with acute asthma exacerbations and the link between sUA and spirometric lung tests.

Patients and methods: This cross-sectional observational study included 120 patients with acute asthma exacerbations and 120 controls, categorized according to peak expiratory flow rate into moderate, and severe and life-threatening asthma. On admission, a detailed history was obtained and investigations were carried out regarding oxygen saturation $\left(\mathrm{SaO}_{2}\right)$, arterial blood gas, spirometry, sUA, number of asthma exacerbations, smoking status, history of previous hospitalization, intensive care unit admission, and mechanical ventilation.

Results: The current study revealed higher sUA in asthmatic patients compared with healthy subjects and in severe asthma patients compared with moderate asthma patients $(P<0.001)$. A positive correlation of sUA with asthma severity, number of asthma exacerbations and smoking index ( $r=0.6,0.42$ and 0.29 , respectively, $P<0.001)$ and a negative correlation of sUA with $\mathrm{SaO}_{2}$, partial pressure of arterial oxygen $\left(\mathrm{PaO}_{2}\right)$, percent predicted forced vital capacity, percent predicted forced expiratory volume (FEV\%) and peak expiratory flow rate percent of predicted (PEFR\%; $r=-0.48,-0.29,-0.44,-0.44$ and -0.66 , respectively, $P<0.001$ ) were observed. Degree of asthma severity, number of asthma exacerbations, and smoking index were significant predictors of high sUA $\left(R^{2}=0.43, P<0.001\right)$ in multiple linear regression model 1. $\mathrm{SaO}_{2}$ and PEFR\% were significant predictors of high uric acid $\left(R^{2}=0.50, P<0.001\right)$ in model 2. The sensitivity and specificity of sUA in predicting severity of asthma at the cutoff point of $6.3 \mathrm{mg} / \mathrm{dL}$ were $80 \%$ and $90 \%$, respectively. The odds ratios of sUA, number of asthma exacerbations, and asthma duration were 5.4, 1.95 and 1.3, respectively.

Conclusion: sUA may be a useful marker of predictive value of severity of asthma exacerbations.

Keywords: asthma, uric acid, exacerbation, spirometery

\section{Introduction}

Asthma is a longstanding inflammation affecting the airways of the lung, which is characterized by wheezing, difficulty breathing, and cough, in addition to the variable limitation of expiratory airflow. ${ }^{1}$

Evidence of an increase in oxidative stress in asthma has been found, ${ }^{2}$ which could produce reactive oxygen that may influence the lungs. ${ }^{3}$ This is because hypoxia (even moderate hypoxia) upregulates xanthine oxidoreductase (XOR) expression, protein abundance and enzymatic activity. The elevation in XOR, especially circulating xanthine oxidase (XO), can lead to a significant enhancement in rates of formation of reactive species, specifically $\mathrm{H}_{2} \mathrm{O}_{2}$ and superoxide. Concomitant with increased $\mathrm{XO}$-dependent 
reactive oxygen species (ROS) formation is serum uric acid (sUA) formation and hence elevation in circulating urate. ${ }^{4}$ Urate is a strong reducing substance and antioxidant, contributing to half of the plasma antioxidative capacity. sUA reacts with ROS and inhibits lipid peroxidation. ${ }^{5}$ Thus, higher sUA levels could be a biomarker of oxidative stress. ${ }^{6}$

Raised sUA levels are associated with tissue hypoxia due to degradation of adenosine. Increased levels of sUA with systemic inflammation were linked with high inflammatory markers (eg, C-reactive protein [CRP] and interleukin-6 [IL-6]). Asthma leads to pulmonary hypoxia as well as elevated inflammatory signaling mediators, both of which elevate XOR expression. ${ }^{7,8}$

Thus, sUA also increases in other diseases such as gout and renal and cardiovascular diseases. ${ }^{9,10}$ Cigarette smoking can induce oxidative stress in addition to lung inflammation, even in healthy individuals. As a result of the extended duration of smoking exposure with subsequent inflammation and lung tissue disruption, pulmonary function is predominantly affected. ${ }^{11}$

\section{Aim of study}

The objectives of the study were to investigate the possibility of sUA level to predict the severity of asthma in adolescents and adults during their acute asthma exacerbations and to identify if there is any link between sUA and pulmonary function tests during these acute exacerbations of asthma.

\section{Patients and methods}

\section{Patients}

This study was conducted at the Chest Department, Pediatric Department, and Intensive Care Unit in Al Ansari Specialist Hospital in Yanbu Al-Sinaiyah, Saudi Arabia, during the period from November 2014 to December 2015. Yanbu Al-Sinaiyah is located in the coastal area of the Red Sea $\sim 350 \mathrm{~km}$ northwest of Jeddah. This young city is a center for modern industries and contains gas separation factories. This study included 120 patients with acute asthma exacerbations (67 males and 53 females), with ages ranging from 13 to 56 years, and 120 healthy age-matched control participants (58 males and 62 females). The patients were further subdivided according to their age into two subgroups: 42 adolescents ( $\leq 18$ years) and 78 adults ( $>18$ years).

Patients with asthma were diagnosed on the basis of medical history, symptoms and physical examination, according to the Global Initiative for Asthma ${ }^{12}$ and the Saudi Initiative for Asthma. ${ }^{13}$ The patients were first categorized according to their clinical assessment, arterial blood gases and measured peak expiratory flow rate percent of predicted (PEFR\%) into mild, moderate, severe, and life-threatening asthma exacerbations. ${ }^{13,14}$ In mild asthma exacerbation, $\mathrm{PEFR} \%$ was $>75 \%$; in moderate exacerbation, PEFR $\%$ was $>50 \%-75 \%$; in severe exacerbation, PEFR $\%$ was $>33 \%-50 \%$ and in life-threatening asthma exacerbation, PEFR\% was $<33 \%$. $^{13,14}$ Then, they were finally classified into two subgroups: a moderate asthma subgroup, and severe and life-threatening asthma subgroup. Alansari Specialist Hospital Departments ethical committee approved this study. A written consent was taken from all participants or their guardians, if they were adolescents or unable to give written consent due to severe or life-threatening asthma.

The exclusion criteria included the following:

1. patients with mild asthma exacerbation;

2. patients with severe acute asthma exacerbation who were unable to do the spirometry test;

3. patients with family history of hyperuricemia and gout;

4. patients treated with xanthine derivatives (eg, theophylline) and diuretics;

5. patients associated with other lung diseases rather than asthma;

6. patients with other life-threatening diseases apart from acute asthma, such as stroke, coronary vascular disease, chronic renal failure, severe liver dysfunction, malignancies, acute gastrointestinal bleeding and advanced multiorgan disorders.

\section{Study design}

The following investigations were carried out in this crosssectional observational study, and they were conducted on admissions of all asthma patients (adolescents and adults):

1. full clinical history and examination, including body mass index (BMI), cigarette smoking status and smoking index (pack-years: daily cigarette pack number $\times$ years of smoking);

2. assessment of severity of asthma exacerbation, and its frequency/year according to Saudi and British guidelines on the management of asthma; ${ }^{13,14}$

3. clinical data on admission to intensive care unit (ICU), duration of hospitalization and connection of mechanical ventilation (MV);

4. oxygen saturation and arterial blood gas analyses by means of a blood gas analyzer: analyzed for hydrogen concentration $(\mathrm{pH})$, partial pressure of arterial oxygen $\left(\mathrm{PaO}_{2}\right)$, partial pressure of arterial carbon dioxide and bicarbonate level; 
5. spirometric lung function test prior to giving bronchodilators to all patients and control participants. Standard techniques were used in measuring forced vital capacity $(\mathrm{FVC} \%)$, forced expiratory volume in 1 second $\left(\mathrm{FEV}_{1} \%\right)$ and $\mathrm{PEFR} \%$, with subjects performing $\mathrm{FVC} \%$ maneuvers on a computerized pulmonary function device (SCHILLER SP-1 computerized pulmonary function apparatus; Baar, Switzerland). ${ }^{15}$ The average cost for spirometric lung function test was 450 Saudi riyals;

6. measurement of sUA in all cases. This test depended on uricase, which is a specific enzyme responsible for the oxidation of sUA. It was determined in a fully automated dimension clinical chemistry system using the instrument's manufacturer's reagents (Siemens Healthcare Diagnostics, Frimley, Camberley, UK). The average cost for the sUA test was 80 Saudi riyals;

7. other laboratory investigations such as complete blood count, renal function test, blood glucose test, serum electrolytes test and hepatic function test.

\section{Statistical analysis}

All statistical analyses were performed using SPSS statistical software, version 20 (IBM Corporation, Armonk, NY, USA). Kolmogorov-Smirnov test was used to test data for continuous variables that follow a normal distribution. Normally distributed numerical variables were presented as mean $\pm \mathrm{SD}$ or median (25-75 interquartile range), if skewed data. Categorical values were expressed as counts and percentages. For comparison between two groups of continuous data, independent $t$-test or Mann-Whitney $U$-test was used, and for comparison between categorical variables, chi-square test was performed.

Correlations between sUA and other variables were performed with two-tailed Pearson's correlation analysis.

Univariate regression analysis was first used to identify other potential significant independent variables such as age, BMI and smoking index that could affect sUA in patients with asthma. Only statistically significant variables $(P<0.05)$ were entered into the multiple stepwise linear regression models to assess whether the severity of asthma still independently predicted high sUA, after correcting for these potential confounders. Owing to the strong association between spirometric and blood gas variables with sUA and severe asthma, two separate models were used to avoid their confounding effects. The following statistically significant clinical and demographic variables were entered into model 1: the sUA as a dependent variable and sex, smoking index, the severity of asthma, the number of asthma exacerbations and asthma duration as independent variables. In model 2 , the statistically significant spirometric and blood gas variables were entered into the model as independent variables and sUA levels as a dependent variable.

The odds ratio (OR) of variables related to severe and life-threatening asthma was estimated by the binary logistic regression model. The Hosmer-Lemeshow (HL) test for logistic regression was used to answer the question, "How well does my model fit the data?". A non-significant $P$-value $(>0.05)$ indicated a well-fitted model to the data.

Sensitivity, specificity and receiver operating characteristic (ROC) curve analyses were performed to evaluate sUA's predictive value of severity of asthma. A boxplot was used to describe the distribution of $\mathrm{sUA}$, according to the severe asthma patient subgroup and the control subjects. For all tests, a significant level of statistics was considered when $P<0.05$.

\section{Results}

The characteristics of adolescent asthma patients and the control subjects are shown in Table 1.

Significant statistical differences were found with regard to smoking index $(P<0.03)$, and highly significant differences were observed in sUA, oxygen saturation, $\mathrm{PO}_{2}$, percent predicted forced vital capacity (FVC\%), $\mathrm{FEV}_{1} \%$ and $\mathrm{PEFR} \%$

Table I Characteristics of asthma adolescent patients and control subjects $(n=84)$

\begin{tabular}{|c|c|c|c|}
\hline Item & $\begin{array}{l}\text { Adolescent } \\
\text { asthma patients } \\
(n=42)\end{array}$ & $\begin{array}{l}\text { Control } \\
\text { subjects } \\
(n=42)\end{array}$ & $P$-value \\
\hline Age, years & $15.4 \pm 1.1$ & $14.9 \pm 1.1$ & $0.773^{a}$ \\
\hline Sex & & & $0.084^{\mathrm{a}}$ \\
\hline Male & $27(64)$ & $22(52)$ & \\
\hline Female & $15(36)$ & $20(48)$ & \\
\hline BMI $\left(\mathrm{kg} / \mathrm{m}^{2}\right)$ & $24.8 \pm 2.1$ & $21.4 \pm 2.3$ & $0.692^{\mathrm{a}}$ \\
\hline Smoking status & & & $0.294^{b}$ \\
\hline Smokers & $6(14)$ & $9(2 \mathrm{I})$ & \\
\hline Non-smokers & $36(86)$ & $33(79)$ & \\
\hline Smoking index (pack-years*) & $2.2 \pm 0.66$ & $2.9 \pm 1.3$ & $0.035^{\mathrm{a}}$ \\
\hline Oxygen saturation (\%) & $92.2 \pm 2.75$ & $96.8 \pm 1.1$ & $<0.00 I^{a}$ \\
\hline $\mathrm{PaO}_{2}$ & $73.5 \pm 7.3$ & $86.3 \pm 1.7$ & $<0.00 I^{a}$ \\
\hline FVC\% & $50.3 \pm 18.3$ & $91.8 \pm 4.5$ & $<0.00 I^{\mathrm{a}}$ \\
\hline $\mathrm{FEV}, \%$ predicted & $53.9 \pm 18.2$ & $87.8 \pm 3.2$ & $<0.001^{\mathrm{a}}$ \\
\hline PEFR\% & $43.7 \pm 13.3$ & $87.8 \pm 5.4$ & $<0.00 \mathrm{I}^{\mathrm{a}}$ \\
\hline $\mathrm{s} \cup A(\mathrm{mg} / \mathrm{dL})$ & $6.33 \pm 0.79$ & $4.79 \pm 0.39$ & $<0.001^{a}$ \\
\hline
\end{tabular}

Notes: Continuous variables are presented as mean \pm SD or $n$ (\%). Categorical variables are numbers with percentages. ${ }^{a}$ Independent $t$-test. ${ }^{b} \mathrm{C}$ hi-square test. $*$ Pack-years $=$ daily cigarette pack number $\times$ years of smoking.

Abbreviations: $\mathrm{BMI}$, body mass index; $\mathrm{PaO}_{2}$, partial pressure of arterial oxygen; $\mathrm{FVC} \%$, percent predicted forced vital capacity; $\mathrm{FEV}_{1} \%$, forced expiratory volume in I second of predicted; PEFR\%, peak expiratory flow rate percent of predicted; sUA, serum uric acid. 
$(P<0.001)$. Similarly, comparison of adult asthma patients and their control subjects have shown the same significant differences (Table 2).

Comparisons between moderate asthma patient subgroup and severe and life-threatening asthma patient subgroup are presented in Table 3. The smoking index, asthma duration, the number of asthma exacerbations, ICU admission, treatment with MV, and hospitalization duration were all significantly higher among the patients with severe and life-threatening asthma $(P<0.001)$. As expected, oxygen saturation, $\mathrm{PaO}_{2}, \mathrm{FVC} \%, \mathrm{FEV}_{1} \%$ and $\mathrm{PEFR} \%$ were all significantly lower in the subgroup of patients with severe and life-threatening asthma than in the moderate asthma subgroup $(P<0.001)$. It is also shown that sUA was statistically significantly higher in the severe and life-threatening, compared to the moderate, asthma subgroup, $6.7 \pm 0.76$ vs 5.64 \pm 0.74 , respectively $(P<0.001)$.

A boxplot distribution of sUA (mg/dL) in asthmatic patient subgroups and healthy controls is illustrated in Figure 1.

As shown in Table 4, correlations were observed between sUA levels and relevant variables in asthmatic patients. Significant positive correlations were identified in the degree of asthma severity, the number of asthma exacerbations and smoking index with sUA ( $r$-coefficients of $0.6,0.42$ and 0.29 ,

Table 2 Characteristics of adult asthma patients and control subjects $(n=156)$

\begin{tabular}{|c|c|c|c|}
\hline Item & $\begin{array}{l}\text { Adult asthma } \\
\text { patients } \\
(n=78)\end{array}$ & $\begin{array}{l}\text { Control } \\
\text { subjects } \\
(n=78)\end{array}$ & $P$-value \\
\hline Age, years & $40 \pm 10$ & $38 \pm 9.8$ & $0.969^{\mathrm{a}}$ \\
\hline Sex & & & $0.097^{\mathrm{b}}$ \\
\hline Male & $40(51)$ & $37(47)$ & \\
\hline Female & $38(49)$ & $4 \mathrm{I}(53)$ & \\
\hline BMI $\left(\mathrm{kg} / \mathrm{m}^{2}\right)$ & $30.8 \pm 7.4$ & $28.7 \pm 5.3$ & $0.035^{\mathrm{a}}$ \\
\hline Smoking status & & & $0.124^{b}$ \\
\hline Smokers & $44(56)$ & $46(59)$ & \\
\hline Non-smokers & $34(44)$ & $32(4 I)$ & \\
\hline Smoking index (pack-years*) & $15(0-25)$ & $15(0-20)$ & $0.028^{c}$ \\
\hline Oxygen saturation (\%) & $90.9 \pm 4.5$ & $96.9 \pm 0.86$ & $<0.00 I^{\mathrm{a}}$ \\
\hline $\mathrm{PaO}_{2}$ & $72.1 \pm 6.4$ & $85 \pm 2.4$ & $<0.00 I^{\mathrm{a}}$ \\
\hline FVC\% & $53.8 \pm 17$ & $85.9 \pm 4.6$ & $<0.00 I^{\mathrm{a}}$ \\
\hline $\mathrm{FEV} \%$ predicted & $54.1 \pm 16$ & $85.5 \pm 5.3$ & $<0.00 I^{\mathrm{a}}$ \\
\hline PEFR\% & $41.7 \pm 16$ & $85.5 \pm 5.2$ & $<0.00 I^{\mathrm{a}}$ \\
\hline $\mathrm{sUA}(\mathrm{mg} / \mathrm{dL})$ & $6.4 \pm 0.97$ & $5.31 \pm 0.49$ & $<0.00 I^{a}$ \\
\hline
\end{tabular}

Notes: Continuous variables are presented as mean \pm SD or $n(\%)$ except smoking index presented as median (interquartile range). Categorical variables are numbers

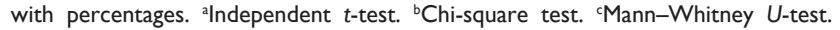
$*$ Pack-years $=$ daily cigarette pack number $\times$ years of smoking.

Abbreviations: $\mathrm{BMI}$, body mass index; $\mathrm{PaO}_{2}$, partial pressure of arterial oxygen; $\mathrm{FVC} \%$, percent predicted forced vital capacity; $\mathrm{FEV}_{1} \%$, forced expiratory volume in I second; PEFR\%, peak expiratory flow rate percent of predicted; sUA, serum uric acid.
Table 3 Comparison of asthmatic patients, according to the severity of asthma in all age groups $(n=120)$

\begin{tabular}{|c|c|c|c|}
\hline Item & $\begin{array}{l}\text { Moderate } \\
\text { asthma } \\
(n=40)\end{array}$ & $\begin{array}{l}\text { Severe and } \\
\text { life-threatening } \\
\text { asthma }(n=80)\end{array}$ & $P$-value \\
\hline Age group, years & & & $0.586^{\mathrm{a}}$ \\
\hline Adolescents $(n=42)$ & $14(35)$ & $28(35)$ & \\
\hline Adults $(n=78)$ & $26(65)$ & $52(65)$ & \\
\hline Sex & & & $0.147^{\mathrm{b}}$ \\
\hline Male & $19(47)$ & $48(60)$ & \\
\hline Female & $21(53)$ & $32(40)$ & \\
\hline BMI $\left(\mathrm{kg} / \mathrm{m}^{2}\right)$ & $29.2 \pm 7.3$ & $28.5 \pm 6.5$ & $0.754^{\mathrm{a}}$ \\
\hline Smoking index (pack-year*) & 0.0 & $15(0-25)$ & $<0.00 \mathrm{I}^{\mathrm{c}}$ \\
\hline Smoking status & & & $0.131^{\mathrm{b}}$ \\
\hline Smokers & $14(35)$ & $38(48)$ & \\
\hline Non-smokers & $26(65)$ & $42(52)$ & \\
\hline Asthma duration (years) & $12.4 \pm 5.8$ & $15.7 \pm 8$ & $<0.043^{\mathrm{a}}$ \\
\hline Asthma exacerbation (n) & $4(2-5)$ & $5(4-6)$ & $<0.002^{\mathrm{a}}$ \\
\hline Oxygen saturation (\%) & $94.9 \pm 0.6$ & $69.3 \pm 5.8$ & $<0.00 I^{a}$ \\
\hline $\mathrm{PaO}_{2}$ & $78.8 \pm 2.6$ & $69(64-72)$ & $0.00 I^{\mathrm{a}}$ \\
\hline FVC $\%$ & $71.5 \pm 10.1$ & $43.1 \pm 11.2$ & $0.00 \mathrm{I}^{\mathrm{a}}$ \\
\hline $\mathrm{FEV}, \%$ predicted & $74.6 \pm 10.5$ & $43.8 \pm 12.3$ & $0.00 \mathrm{I}^{\mathrm{a}}$ \\
\hline PEFR\% & $58.8 \pm 2.85$ & $34.1 \pm 9.3$ & $0.00 I^{a}$ \\
\hline $\mathrm{sUA}(\mathrm{mg} / \mathrm{dL})$ & $5.64 \pm 0.74$ & $6.7 \pm 0.76$ & $0.00 I^{\mathrm{a}}$ \\
\hline ICU admission & & & $<0.00 \mathrm{I}^{\mathrm{b}}$ \\
\hline No & $40(100)$ & $20(25)$ & \\
\hline Yes & None & $60(75)$ & \\
\hline MV & & & $<0.00 \mathrm{I}^{\mathrm{b}}$ \\
\hline No & $40(100)$ & $60(75)$ & \\
\hline Yes & None & $20(25)$ & \\
\hline $\begin{array}{l}\text { Hospitalization duration } \\
\text { (days) }\end{array}$ & $2.9 \pm 0.7$ & $5.1 \pm 1.9$ & $<0.00 I^{a}$ \\
\hline
\end{tabular}

Notes: Continuous variables are presented as mean \pm SD or $\mathrm{n}(\%)$ except smoking index presented as median (interquartile range). Categorical variables are numbers with percentages. ${ }^{a}$ Independent $t$-test. ${ }^{b}$ Chi-square test. ${ }^{C}$ Mann-Whitney U-test. *Pack-years $=$ daily cigarette pack number $\times$ years of smoking.

Abbreviations: $\mathrm{BMI}$, body mass index; $\mathrm{PaO}_{2}$, partial pressure of arterial oxygen; $\mathrm{FVC} \%$, percent predicted forced vital capacity; $\mathrm{FEV} \%$, forced expiratory volume in I second; PEFR\%, peak expiratory flow rate percent of predicted; sUA, serum uric acid; ICU, intensive care unit; MV, mechanical ventilation.

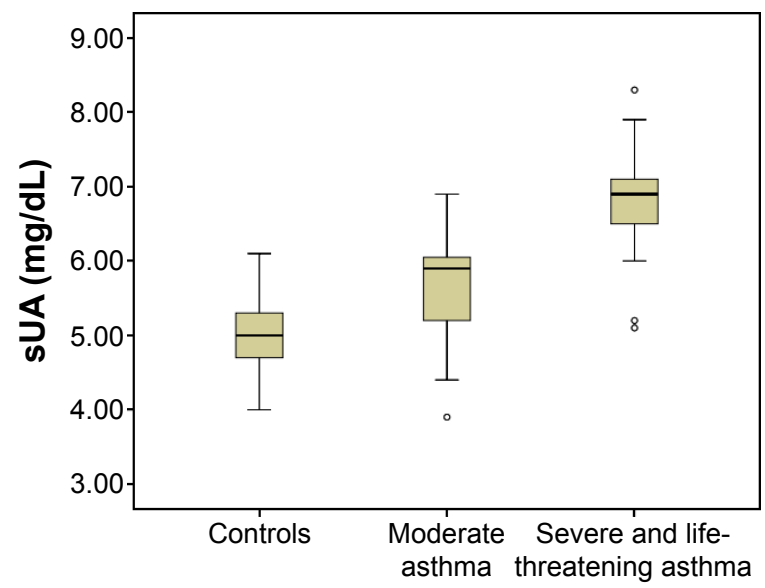

Figure I A boxplot distribution of $\mathrm{sUA}(\mathrm{mg} / \mathrm{dL})$ in controls, moderate asthma patients and severe and life-threatening asthma patients in all age groups.

Notes: Boxplot explanation: upper horizontal line of box $=75$ th percentile, lower horizontal line of box $=25$ th percentile, horizontal bar within box $=$ median, square within box $=$ mean, and vertical lines out of the box $=$ minimum and maximum. $P$-value $<0.001$.

Abbreviation: sUA, serum uric acid. 
Table 4 Correlations between sUA levels and relevant variables in asthmatic patients

\begin{tabular}{lll}
\hline Item & r-coefficient & $P$-value \\
\hline Age, years & 0.02 & 0.864 \\
$\mathrm{BMI}\left(\mathrm{kg} / \mathrm{m}^{2}\right)$ & 0.07 & 0.440 \\
Smoking index & 0.29 & 0.001 \\
Asthma duration & 0.15 & 0.106 \\
Degree of severity of asthma & 0.60 & $<0.00$ I \\
Number of asthma exacerbations & 0.42 & $<0.00$ I \\
Oxygen saturation $(\%)$ & -0.48 & $<0.00$ I \\
$\mathrm{PaO}_{2}$ & -0.29 & $<0.00 \mathrm{I}$ \\
FVC\% & -0.44 & $<0.00 \mathrm{I}$ \\
FEV $\%$ predicted & -0.44 & $<0.00 \mathrm{I}$ \\
PEFR\% & -0.66 & $<0.00 \mathrm{I}$ \\
\hline
\end{tabular}

Abbreviations: sUA, serum uric acid; $r$, Pearson correlation coefficient; BMI, body mass index; $\mathrm{PaO}_{2}$, partial pressure of arterial oxygen; $\mathrm{FVC} \%$, percent predicted forced vital capacity; FEV \%, forced expiratory volume in I second; PEFR\%, peak expiratory flow rate percent of predicted.

respectively; $P<0.001)$. Significant negative correlations of sUA with oxygen saturation, $\mathrm{PaO}_{2}$ and spirometric parameters $\left(\mathrm{FVC} \%, \mathrm{FEV}_{1} \%\right.$ predicted and $\left.\mathrm{PEFR} \%\right)$ were demonstrated with $r$-coefficients of $-0.48,-0.29,-0.44,-0.44$ and -0.66 , respectively $(P<0.001)$.

To establish the likely predictors of high sUA in all asthma patients, first, a univariate regression analysis was done to identify separately the relevant risk factors predicting high sUA (Table 5). Second, only significant risk factors $(P<0.05)$ were entered into the multiple linear regression models. In model 1 , the clinical and demographic variables were entered. It was observed that the degree of asthma severity, the number of asthma exacerbations and smoking index were significant predictive risk factors, explaining $43 \%$ of

Table 5 Univariate regression analysis to identify variables predicting high sUA in asthmatic patients $(n=120)$

\begin{tabular}{llll}
\hline Variable & $\beta$ & $\boldsymbol{t}$ & $\boldsymbol{P}$-value \\
\hline Age, years & 0.02 & 0.25 & 0.806 \\
$\mathrm{Sex}$ & 0.26 & 2.94 & $<0.004$ \\
$\mathrm{BMI}\left(\mathrm{kg} / \mathrm{m}^{2}\right)$ & 0.07 & 0.77 & $0.44 \mathrm{I}$ \\
Smoking index & 0.29 & $3.3 \mathrm{I}$ & $<0.00 \mathrm{I}$ \\
Degree of severity of asthma & 0.60 & 8.25 & $<0.00 \mathrm{I}$ \\
Number of asthma exacerbations & 0.42 & 5.05 & $<0.00 \mathrm{I}$ \\
Duration of asthma & 0.15 & 1.64 & 0.105 \\
FVC\% & -0.46 & -5.66 & $<0.00 \mathrm{I}$ \\
FEV \% predicted & -0.44 & -5.37 & $<0.00 \mathrm{I}$ \\
PEFR\% & -0.66 & -9.53 & $<0.00 \mathrm{I}$ \\
Oxygen saturation $(\%)$ & -0.48 & -5.94 & $<0.00 \mathrm{I}$ \\
PaO & -0.29 & -3.29 & $<0.00 \mathrm{I}$ \\
\hline
\end{tabular}

Abbreviations: sUA, serum uric acid; BMI, body mass index; FVC\%, percent predicted forced vital capacity; FEV \%, forced expiratory volume in I second; PEFR\%, peak expiratory flow rate percent of predicted; $\mathrm{PaO}_{2}$, partial pressure of arterial oxygen.
Table 6 Multiple linear regression for sUA-level predictors in the serum of asthmatic patients $(n=120)$

\begin{tabular}{llll}
\hline Variable & $\beta$ & $\boldsymbol{t}$ & \multicolumn{1}{c}{$\boldsymbol{P}$-value } \\
\hline Model I: clinical and demographic variables & & \\
Sex & 0.08 & 1.01 & 0.310 \\
Smoking index & 0.18 & 2.09 & $<0.036$ \\
Severe and life-threatening asthma & $0.5 \mathrm{I}$ & 6.07 & $<0.00 \mathrm{I}$ \\
Number of asthma exacerbations & 0.14 & 1.64 & $<0.052$ \\
Duration of asthma & -0.04 & -1.2 & 0.224 \\
Constant & - & 7.80 & $<0.00 \mathrm{I}$ \\
Model 2: spirometric and blood gas variables & & \\
FVC\% & -0.26 & -1.34 & 0.187 \\
FEV\% predicted & 0.34 & 1.68 & 0.092 \\
PEFR\% & -1.17 & -7.06 & $<0.000 \mathrm{I}$ \\
Oxygen saturation (\%) & 0.43 & 3.62 & $<0.003$ \\
PaO & 0.02 & 1.28 & $0.24 \mathrm{I}$ \\
Constant & - & 14.3 & $<0.00 \mathrm{I}$ \\
\hline
\end{tabular}

Abbreviations: sUA, serum uric acid; FVC\%, percent predicted forced vital capacity; FEV \%, forced expiratory volume in I second; PEFR\%, peak expiratory flow rate percent of predicted; $\mathrm{PaO}_{2}$, partial pressure of arterial oxygen.

the variability of $\operatorname{sUA}\left(R=0.65, R^{2}=0.43, F=17.07, P<0.001\right)$. In model 2 , the spirometric and blood gas variables were entered, and it was observed that oxygen saturation and PEFR \% were significant predictive risk factors of high sUA $\left(R=0.71, R^{2}=0.50, F=22.88, P<0.001\right.$; Table 6).

Figure 2 and Table 6 show the area under the ROC curve of 0.87 (95\% confidence interval [CI] 0.81-0.94, $P<0.001$ ). Also used to reach the optimal cutoff point (with the maximal

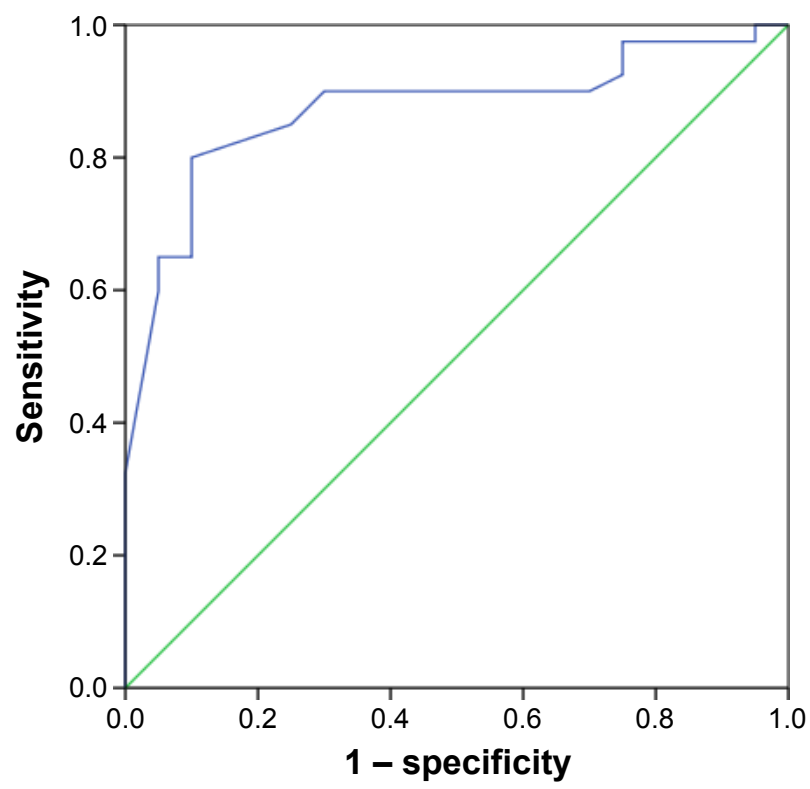

Figure 2 ROC curve for evaluating the prognostic performance of sUA in asthma severity in all age groups.

Abbreviations: ROC, receiver operating characteristic; sUA, serum uric acid. 
Table 7 ROC: sensitivity and specificity of sUA as a predictive value of asthma severity

\begin{tabular}{lllll}
\hline & $\begin{array}{l}\text { Cutoff } \\
\text { point }\end{array}$ & $\begin{array}{l}\text { Area under the } \\
\text { curve }(95 \% \mathrm{Cl})\end{array}$ & $\begin{array}{l}\text { Sensitivity } \\
(\mathbf{9 5 \%} \mathrm{Cl})\end{array}$ & $\begin{array}{l}\text { Specificity } \\
(\mathbf{9 5 \%} \mathrm{Cl})\end{array}$ \\
\hline $\begin{array}{l}\mathrm{s} \mathrm{A} A \\
(\mathrm{mg} / \mathrm{dL})\end{array}$ & 6.3 & $0.87(0.8 \mathrm{I}-0.94)$ & $80 \%(70 \%-88 \%)$ & $90 \%(77 \%-97 \%)$ \\
\hline
\end{tabular}

Note: $P<0.001$.

Abbreviations: $R O C$, receiver operating characteristic; sUA, serum uric acid; $\mathrm{Cl}$, confidence interval.

sensitivity and specificity) of sUA levels associated with severity of asthma. The optimal cutoff point was $6.3 \mathrm{mg} / \mathrm{dL}$, at which the sensitivity and specificity, with $95 \% \mathrm{CI}$, of sUA as a predictor of severity of asthma were $80 \%(70 \%-88 \%)$ and $90 \%(77 \%-97 \%)$, respectively (Table 7).

Finally, binary logistic regression analysis was done to verify whether high sUA could be a risk factor for severe and life-threatening asthma. It was demonstrated that sUA, number of asthma exacerbations and asthma duration had ORs (95\% CI) of 5.4 (2.5-8.6), 1.95 (1.5-5.7) and $1.3(1.2-1.9)$ with $P<0.001, P<0.002$ and $P<0.05$, respectively. A wellfitted model was shown by a non-significant $P$-value by the HL test $(P=0.48$; Table 8$)$.

\section{Discussion}

This study clarified the utility of sUA as a predictive marker in adolescents and adults with severe and life-threatening asthma exacerbations. Recently, a small number of studies ${ }^{16,17}$ have highlighted the link between asthma and sUA. Some interesting studies revealed alterations in the level of sUA in the asthma patient's airways and in experimental animals. ${ }^{1718}$ Our study reports that patients generally with acute asthma exacerbations had a higher sUA as compared to healthy controls $(P<0.001)$. Moreover, patients experiencing severe and life-threatening asthma had a higher sUA compared with patients with moderate asthma, $6.7 \pm 0.76$ vs $5.6 \pm 0.74$ $(P<0.001)$. Our results were comparable to data from Li et al ${ }^{19}$ and Sayyah. ${ }^{20}$

Table 8 The OR of variables related to severe and life-threatening asthma, estimated by the binary logistic regression model

\begin{tabular}{lll}
\hline & OR $^{\text {a }}(95 \% \mathrm{Cl})$ & $P$-value \\
\hline Constant & $0.000 I$ & $<0.00 I$ \\
sUA & $5.4(2.5-8.6)$ & $<0.001$ \\
Number of asthma exacerbations & $1.95(1.5-5.7)$ & $<0.002$ \\
Asthma duration & $1.3(1.2-1.9)$ & $<0.050$ \\
\hline
\end{tabular}

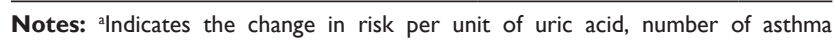
exacerbations and asthma duration. HL test $(P=0.483)$.

Abbreviations: OR, odds ratio; $\mathrm{Cl}$, confidence interval; sUA, serum uric acid; HL, Hosmer-Lemeshow.
The high sUA in patients with acute asthma exacerbations can be explained by the following:

1. The inflammation associated with cell apoptosis and necrosis will cause an increase in the metabolites of purine nucleotides (DNA and RNA) and will enhance the enzyme activity of xanthine oxidase with an increase in sUA concentration. . $^{21,22}$

2. Hypoxia leads to high adenosine triphosphate degradation (a purine nucleotide source) with an increased production of sUA by XO. ${ }^{22-24}$

Many studies reported a frequent relationship between high sUA and inflammatory markers, particularly those induced by the recent acute inflammation. Therefore, it was not surprising to detect high sUA alongside elevated CRP, tumor necrosis factor- $\alpha$ and IL-6 in many inflammatory diseases. ${ }^{7,25-27}$

In the present study, significant positive correlations were demonstrated between sUA and number of asthma exacerbations $(r=0.42)$ and cigarette smoking index $(r=0.29)$. Conversely, significant negative correlations were demonstrated between oxygen saturation $(r=-0.48)$, $\mathrm{PaO}_{2}(r=-0.29), \mathrm{FVC} \%(r=-0.44), \mathrm{FEV}_{1} \%$ predicted $(r=-0.44)$, PEFR\% $(r=-0.66)$ and sUA levels. Li et al ${ }^{19}$ similarly reported a significant association of sUA levels with impaired lung function. Furthermore, a Japanese study ${ }^{27}$ revealed a considerable link between spirometric indices and sUA. The following proposed mechanisms may explain the negative correlations between sUA and spirometric parameters: first, tissue hypoxia during asthma exacerbation induces the production of sUA, and second, high levels of sUA may enhance lung inflammation, which eventually impairs pulmonary function..$^{27,28}$

Finally, in the current study, the sensitivity and specificity of sUA as a predictive of the severity of asthma were found to be $80 \%$ and $90 \%$, respectively, at the cutoff point of $6.3 \mathrm{mg} / \mathrm{dL}$, and the zone beneath the curve was $0.87(P<0.001)$. Furthermore, a binary logistic regression model for the calculation of an OR related to severe and life-threatening asthma showed that sUA, the number of asthma exacerbations, and asthma duration had an OR of $5.4(P<0.001), 1.95(P<0.002)$ and $1.3(P<0.05)$, respectively.

Therefore, it can be concluded that sUA may be used as a useful non-invasive prognostic indicator of the severity of asthma exacerbation.

In turn, the possibility of the presence of other covariates could affect the sUA level in patients with acute asthma exacerbations in the current study. The multiple linear regression model's clinical and demographic variables revealed 
that besides severe asthma, smoking and the number of asthma exacerbations are predictive of high sUA. In model 2, "spirometry and blood gas variables", low PEFR\% and oxygen saturation were also predictive of high sUA. It is known that there are other factors that could affect sUA such as sex, BMI, cigarette smoking and chronic lung, kidney and cardiovascular diseases. ${ }^{29-31}$

In contrast to the current study, a couple of studies ${ }^{32,33}$ reported a low sUA and other antioxidant compounds such as vitamin $\mathrm{C}$ and vitamin $\mathrm{E}$ in asthmatic patients. This contradiction may be explained partly by the following:

1. Various factors could affect the serum level of sUA, including cardiac and vascular diseases, type of food ingested, cigarette smoking, renal insufficiency and hereditary metabolic disorders of purine. ${ }^{34}$

2. The differences in the patients studied, as one study was in adults and the other was in children with asthma. ${ }^{28}$

3. The existence of an additional antioxidant deficiency such as vitamin D or vitamin C, which may be linked simultaneously to asthma severity. ${ }^{32,33,35}$

4. sUA is one of the non-enzymatic antioxidants during an asthma exacerbation. It acts as a protective mechanism against the lung damage by large amounts of oxidants. Reduction of sUA could be an indicator of the reduced capability of the antioxidant defense system in patients with acute asthma exacerbations. ${ }^{36-38}$

The present study was not without limitations, as other antioxidant deficiencies, for example, selenium and some vitamins were not evaluated in this study, which may coexist in asthmatic patients and may affect the severity of asthma. Thus, further large prospective studies are necessary to clarify the connection of sUA with the severity of asthma.

\section{Conclusion}

High sUA has a significant positive correlation with severe and life-threatening asthma and a negative correlation with spirometric pulmonary functions in adolescents and adults. It may be a predictive value of severity of asthma. However, other comorbid factors such as the number of asthma exacerbations, asthma duration and cigarette smoking have also been shown to affect the sUA level and should be considered.

In view of the results of this study, sUA may be considered as an accessible, useful and low-cost marker of the severity of asthma exacerbations.

\section{Disclosure}

The authors report no conflicts of interest in this work.

\section{References}

1. GINA 2014. Global Initiative for Asthma. Available from: http://www. benhviennhi.org.vn/upload/files/GINA\%202014.pdf. Accessed August $12,2015$.

2. Dut R, Dizdar EA, Birben E, et al. Oxidative stress and its determinants in the airways of children with asthma. Allergy. 2008;63(12): 1605-1609.

3. Bowler RP, Crapo JD. Oxidative stress in the airways: is there a role for extracellular superoxide dismutase? Am J Respir Crit Care Med. 2002;166(12 pt 2):S38-S43.

4. Kelley EE, Hock T, Khoo NK, et al. Moderate hypoxia induces xanthine oxidoreductase activity in arterial endothelial cells. Free Radic Biol Med. 2006;40(6):952-959.

5. Glantzounis GK, Tsimoyiannis EC, Kappas AM, Galaris DA. Uric acid and oxidative stress. Curr Pharm Des. 2005;11(14):4145-4151.

6. Muraoka S, Miura T. Inhibition by the uric acid of free radicals that damage biological molecules. Pharmacol Toxicol. 2003;93(6):284-289.

7. Ruggiero $\mathrm{C}$, Cherubini A, Ble A, et al. Uric acid and inflammatory markers. Eur Heart J. 2006;27(10):1174-1181.

8. Ruggiero C, Cherubini A, Miller E 3rd, et al. Usefulness of uric acid to predict changes in C-reactive protein and interleukin-6 in a 3-year period in Italians aged 21-98 years. Am J Cardiol. 2007;100(1):115-121.

9. Feig D, Mazzali M, Kang DH, et al. Serum uric acid: a risk factor and a target for treatment. J Am Soc Nephrol. 2006;17(4 suppl 2):S69-S73.

10. Heining M, Johnson RJ. The role of uric acid in hypertension, renal disease, and metabolic syndrome. Cleve Clin J Med. 2006;73(12): 1059-1064.

11. Vestbo J, Hurd SS, Agustı AG, et al. Global strategy for the diagnosis, management and prevention of chronic obstructive pulmonary disease, GOLD executive summary. Am J Respir Crit Care Med. 2013;187(4): $347-365$.

12. Global Initiative for Asthma (GINA) [homepage on the Internet]. 2012. Available from: http://www.ginasthma.org. Accessed May 29, 2015.

13. Saudi Initiative for Asthma (SINA) [homepage on the Internet]. 2012 Available from: http://sinagroup.org/. Accessed May 29, 2015.

14. British Thoracic Society [webpage on the Internet]. British Guideline on the Management of Asthma. 2014. Available from: https://www. brit-thoracic.org.uk/document-library/clinical-information/asthma/ btssign-asthma-guideline-2014/. Accessed May 29, 2015.

15. ATS. ATS/ERS Task Force Standardisation of Lung Function Testing: Interpretative Strategies for Lung Function Tests. 2005. Available from: http://www.thoracic.org/statements/resources/pft/pft5.pdf. Accessed September 9, 2016.

16. Kool M, Willart MA, van Nijmegen M, et al. An unexpected role for uric acid as an inducer of T helper 2 cell immunity to inhaled antigens and inflammatory mediator of allergic asthma. Immunity. 2011;34(4):527-540.

17. Gasse P, Riteau N, Charron S, et al. Uric acid is a danger signal activating NALP3 inflammasome in lung injury inflammation and fibrosis. Am J Respir Crit Care Med. 2009;179(10):903-913.

18. Martinon F, Pétrilli V, Mayor A, Tardivel A, Tschopp J. Gout-associated uric acid crystals activate the NALP3 inflammasome. Nature. 2006;440(7081):237-241.

19. Li L, Wan C, Wen F. An unexpected role for serum uric acid as a biomarker for severity of asthma exacerbation. Asian Pac J Allergy Immunol. 2014;32(1):93-99.

20. Sayyah SG. Serum uric acid level in the blood of asthmatic patients in Basrah governorate. J Basrah Res. 2014;40:138-145.

21. Wu JT, Wu LL. Chronic systemic inflammation leading eventually to myocardial infarction, stroke, COPD, renal failure and cancer is induced by multiple risk factors. J Biomed Lab Sci. 2007;19:1-6.

22. Page S, Powell D, Benboubetra M, et al. Xanthine oxidoreductase in human mammary epithelial cells: activation in response to inflammatory cytokines. Biochim Biophys Acta. 1998;1381(2):191-202.

23. Sato N, Kurashima K, Ubukata M, et al. Prognostic significance of serum uric acid in patients with chronic obstructive pulmonary disease receiving home oxygen therapy. Nihon Kokyuki Gakkai Zasshi. 2003;41(2): 74-80. 
24. Braghiroli A, Sacco C, Erbetta M, Ruga V, Donner CF. Overnight urinary uric acid: creatinine ratio for detection of sleep hypoxemia. A validation study in chronic obstructive pulmonary disease and obstructive sleep apnea before and after treatment with nasal continuous positive airway pressure. Am Rev Respir Dis. 1993;148(1):173-178.

25. Caravaca F, Martín MV, Barroso S, et al. Serum uric acid and C-reactive protein levels in patients with chronic kidney disease. Nefrologia. 2005; 25(6):645-654.

26. Kanellis J, Kang DH. Uric acid as a mediator of endothelial dysfunction, inflammation, and vascular disease. Semin Nephrol. 2005;25(1): 39-42.

27. Aida Y, Shibata Y, Osaka D, et al. The relationship between serum uric acid and spirometric values in participants in a health check: the Takahata study. Int J Med Sci. 2011;8(6):470-478.

28. Garcia-Pachon E, Padilla-Navas I, Shum C. Serum uric acid to creatinine ratio in patients with thechronic obstructive pulmonary disease. Lung. 2007; 185(1):21-22.

29. Conen D, Wietlisbach V, Bovet $\mathrm{P}$, et al. Prevalence of hyperuricemia and relation of serum uric acid with cardiovascular risk factors in a developing country. BMC Public Health. 2004;4:9.

30. Nan H, Qiao Q, Soderberg S, et al. Serum uric acid and components of the metabolic syndrome in non-diabetic populations in Mauritian Indians and Creoles and in Chinese in Qingdao, China. Metab Syndr Relat Disord. 2008;6(1):47-57.
31. Rathmann W, Haastert B, Icks A, Giani G, Roseman JM. Ten-year change in serum uric acid and its relation to changes in other metabolic risk factors in young black and white adults: the cardia study. Eur $J$ Epidemiol. 2007;22(7):439-445.

32. Al-Abdulla NO, Al Naama LM, Hassan MK. Antioxidant status in an acute asthmatic attack in children. J Pak Med Assoc. 2010;60(12): 1023-1027.

33. Anetor JI, Ajose OA, Ige O, Oyeleye AO, Ojo PO. Antioxidant status of adult Nigerian asthmatics: implications for prognosis. Nutr Health. 2003; 17(3):221-229.

34. Feig DI, Kang DH, Johnson RJ. Uric acid and cardiovascular risk. N Engl J Med. 2008;359(17):1811-1821.

35. Misso NLA, Brooks-Wildhaber J, Ray S, Vally H, Thompson PJ. Plasma concentrations of dietary and non dietary antioxidants are low in severe asthma. Eur Respir J. 2005;26(2):257-264.

36. Dweik RA, Comhair SA, Gaston B, et al. NO chemical events in the human airway during the immediate and lateantigen-induced asthmatic response. Proc Natl Acad Sci U S A. 2001;98(5):2622-2627.

37. Comhair SA, Erzurum SC. Redox control of asthma: molecular mechanisms and therapeutic opportunities. Antioxid Redox Signal. 2010;12(1): 93-124.

38. Sahiner UM, Birben E, Erzurum S, Sackesen C, Kalayci O. Oxidative stress in asthma. WAO J. 2011;4(10):151-158.
Therapeutics and Clinical Risk Management

\section{Publish your work in this journal}

Therapeutics and Clinical Risk Management is an international, peerreviewed journal of clinical therapeutics and risk management, focusing on concise rapid reporting of clinical studies in all therapeutic areas outcomes, safety, and programs for the effective, safe, and sustained use of medicines. This journal is indexed on PubMed Central, CAS,

\section{Dovepress}

EMBase, Scopus and the Elsevier Bibliographic databases. The manuscript management system is completely online and includes a very quick and fair peer-review system, which is all easy to use. Visit http://www.dovepress.com/testimonials.php to read real quotes from published authors. 